\title{
Timing and route of enteral tube feeding did not affect death or combined death or poor outcome in stroke and dysphagia
}

Dennis MS, Lewis SC, Warlow C. Effect of timing and method of enteral tube feeding for dysphagic stroke patients (FOOD): a multicentre randomised controlled trial. Lancet 2005;365:764-72.

Q In patients with recent stroke and dysphagia, does early initiation of enteral tube feeding (ETF) ( $v$ no tube feeding for $\geqslant 7$ d) improve outcomes (study 1)? In these patients, does ETF by percutaneous endoscopic gastrostomy (PEG) ( $v$ nasogastric [NG] tube) improve outcomes (study 2)?

\section{METHODS}

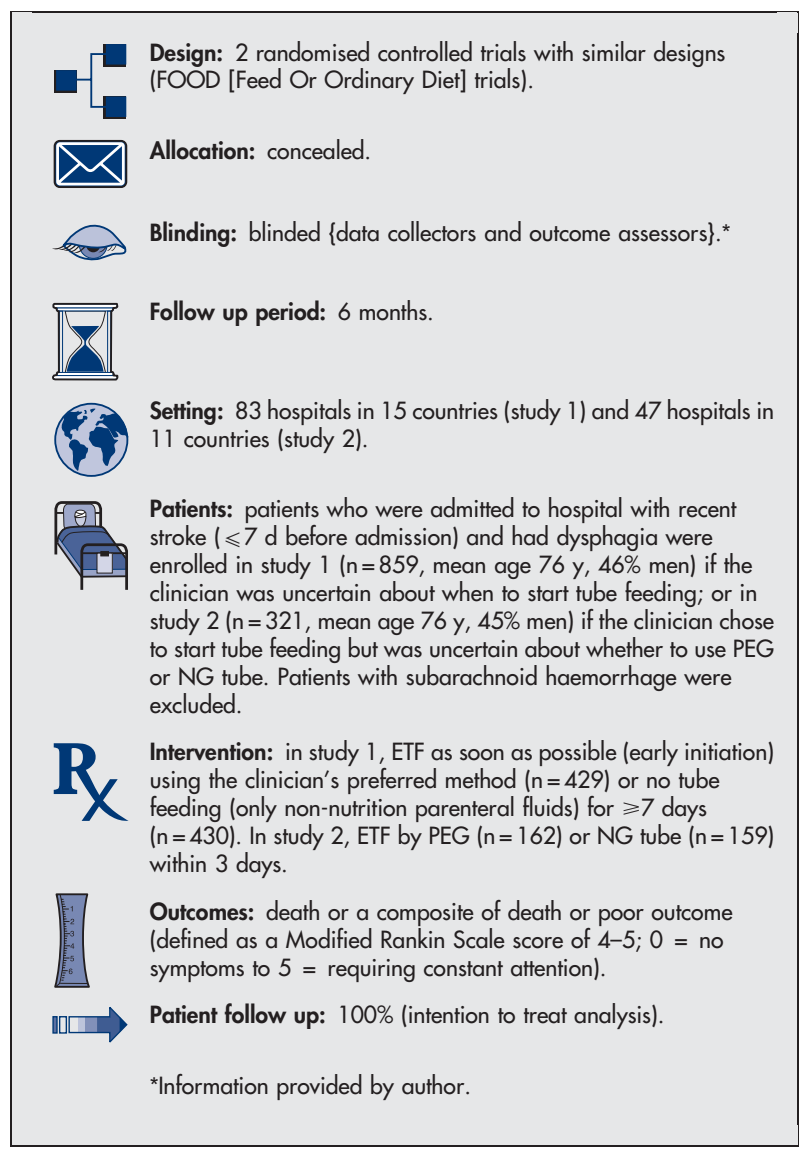

For correspondence: Professor $M$ Mennis, Western General Hospital, Edinburgh, UK. martin.dennis@ed.ac.uk

Sources of funding: National Health Service Research and Development, UK; Stroke Association; Chief Scientist Office of the Scottish Executive; Chest, Heart, and Stroke, Scotland; Singapore Medical Research Council; and Royal Australasian College of Physicians.

\section{MAIN RESULTS}

Study 1: early initiation of ETF did not reduce death or the composite of death or poor outcome more than no tube feeding for $\geqslant 7$ days (table). Study 2: ETF by PEG did not reduce death or the composite of death or poor outcome more than ETF by NG tube (table).

\section{CONCLUSION}

In patients with recent stroke and dysphagia, early initiation of enteral tube feeding (ETF) did not differ from no tube feeding for $\geqslant 7$ days for death or the combined outcome of death or poor outcome, and ETF by percutaneous endoscopic gastrostomy did not differ from ETF by nasogastric tube for death or the combined outcome of death or poor outcome.

\section{A modified version of this abstract appears in ACP Journal Club.}

\section{Commentary}

$\mathrm{T}$ here is no consensus on the timing and route of tube feeding in patients with stroke and dysphagia. ETF by NG tube or PEG is usually initiated within 7-10 days after recognition of insufficient oral intake. It is unclear whether the nutritional benefits of early feeding (ie, within the first 3-7 d) offset the potential complications of sustained ETF. Because of this uncertainty, tube feeding can sometimes be delayed for $\geqslant 2$ weeks. Considerable uncertainty also exists, except in uncooperative or confused stroke patients, about whether PEG feeding is preferable to use of an NG tube.

The 2 trials by Dennis et al addressed these issues and showed a clinically significant advantage of NG tube feeding, either early $(<7$ d) as opposed to late ( $\geqslant 7 \mathrm{~d}$ ), or as an alternative to feeding by PEG. However, the trial results convey mixed messages for clinicians: patients receiving early NG tube feeding had better survival but in a more disabled state (study 1). Patients receiving feeding by NG tube rather than PEG had better survival, functioning, and overall quality of life, with fewer pressure sores (study 2). Furthermore, a greater incidence of gastrointestinal haemorrhages was observed in the NG tube groups in both trials, possibly because of direct trauma to the mucosa or from aspirin use. The authors recommend NG tube feeding within the first few days of admission and, in case of practical objections (eg, confusion or inability to tolerate a NG tube), within the first 2 or 3 weeks. Overall, the message is that NG tube feeding can be initiated early and maintained safely without increased risk of complications such as aspiration pneumonia. Robert Lindeboom, RN, PhD Academic Medical Center, Amsterdam, The Netherlands

Timing and method of enteral tube feeding (ETF) in stroke and dysphagia*

\begin{tabular}{|c|c|c|c|c|c|}
\hline Study & Comparisons & Outcomes at 6 mo & Event rates & $\operatorname{RRR}(95 \% \mathrm{Cl})$ & NNT \\
\hline \multirow[t]{2}{*}{1} & Early initiation of ETF $v$ no ETF for $\geqslant 7 d$ & $\begin{array}{l}\text { Death } \\
\text { Death or poor outcome }\end{array}$ & $\begin{array}{l}42 \% \text { v } 48 \% \\
79 \% \text { v } 80 \%\end{array}$ & $\begin{array}{c}12 \%(-2 \text { to } 24) \\
1 \%(-5 \text { to } 8)\end{array}$ & $\begin{array}{l}\text { Not significant } \\
\text { Not significant }\end{array}$ \\
\hline & & & & RRI (CI) & NNH \\
\hline 2 & ETF by PEG $v$ ETF by NG tube & $\begin{array}{l}\text { Death } \\
\text { Death or poor outcome }\end{array}$ & $\begin{array}{l}49 \% \vee 48 \% \\
89 \% \vee 81 \%\end{array}$ & $\begin{array}{l}2 \%(-19 \text { to } 28) \\
10 \%(-1 \text { to } 21)\end{array}$ & $\begin{array}{l}\text { Not significant } \\
\text { Not significant }\end{array}$ \\
\hline
\end{tabular}

*PEG = percutaneous endoscopic gastrostomy; NG = nasogastric. Other abbreviations defined in glossary; RRR, RRI, NNT, NNH, and Cl calculated from data in article. 